GA-A15801

UC-20

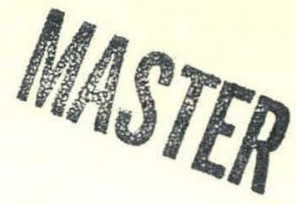

\title{
PRELIMINARY RESULTS OF NONCIRCULAR PLASMA EXPERIMENTS IN DOUBLET III
}

\author{
by \\ TIHIRO OHKAWA
}

FEBRUARY 1980

\section{GENERAL ATOMIC COMPANY}




\section{DISCLAIMER}

This report was prepared as an account of work sponsored by an agency of the United States Government. Neither the United States Government nor any agency Thereof, nor any of their employees, makes any warranty, express or implied, or assumes any legal liability or responsibility for the accuracy, completeness, or usefulness of any information, apparatus, product, or process disclosed, or represents that its use would not infringe privately owned rights. Reference herein to any specific commercial product, process, or service by trade name, trademark, manufacturer, or otherwise does not necessarily constitute or imply its endorsement, recommendation, or favoring by the United States Government or any agency thereof. The views and opinions of authors expressed herein do not necessarily state or reflect those of the United States Government or any agency thereof. 


\section{DISCLAIMER}

Portions of this document may be illegible in electronic image products. Images are produced from the best available original document. 


\title{
NOTICE
}

This report was prepared as an account of work sponsored by an agency of the United States Government. Neither the United States nor any agency thereof, nor any of their employees, makes any warranty, expressed or implied, or assumes any legal liability or responsibility for any third party's use or the results of such use of any information, apparatus, product or process disclosed in this report, or represents that its use by such third party would not infringe privately owned rights.

\author{
Printed in the United States of America \\ Available from \\ National Technical Information Service \\ U. S. Department of Commerce \\ 5285 Port Royal Road \\ Springfield, Virginia 22161
}

NTIS Price Code: Printed Copy A02; Microfiche A01 
GA-A15801

UC-20

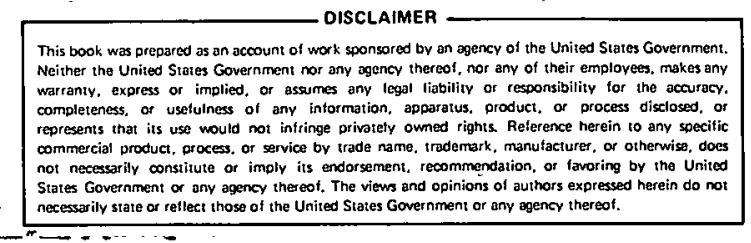

PRELIMINARY RESULTS OF NONCIRCULAR PLASMA EXPERIMENTS IN DOUBLET III

\author{
by \\ TIHIRO OHKAWA
}

Presented at the International School of Plasma Physics Workshop on "Physics of Plasmas Close to Thermonuclear Conditions," August 27 to September 8, 1979, Varenna, Italy. To be printed in the Proceedings.

\author{
Work supported by \\ Department of Energy \\ Contract DE-AT03-76ET51011
}

\title{
GENERAL ATOMIC PROJECT 3235
}

FEBRUARY 1980

\section{GENERAL ATOMIC COMPANY}




\section{PRELIMINARY RESULTS OF NONCIRCULAR PLASMA EXPERIMENTS IN DOUBLET III*}

\section{T. Ohkawa}

General Atomic Company

San Diego, California

U.S.A.

\section{ABSTRACT}

Preliminary results of noncircular plasma experiments in Doublet III are reported. Shaping and discharge characteristics in doublet plasmas with high-Z limiters are described. Electron energy confinement and maximum plasma density are in agreement with standard circular tukällak eimpirical scaling laws. Chromium and moly= bdenum appear to be the dominant high-Z contaminants while carbon appears to dominate low-Z contaminants. High-Z impurity radiation does not appear to dominate the central power balance.

\section{KEY WORDS}

machine parameters, plasma shaping, discharge characteristics, electron confinement, maximum plasma density, impurities

\section{INTRODUCTION}

It is now generally acknowledged that operation with a noncircular plasma crosssection will be a necessary feature of a tokamak fusion power reactor. The feasibility of shaping plasmas into vertically elongated configurations and the effects of this shaping on plasma stability and confinement have been investigated at General Atomic Company in a series of noncircular tokamak experiments beginning in 1968 (Fisher and co-workers, 1977; Jensen and co-workers, 1975; Ohkawa and Voorhies, 1969). Doublet III is the third and most ambitious of this series, and is specifically designed to study the effects of noncircularity in high-beta, auxiliary-heated plasmas, wltimately with reactor-like parameters.

Ohmic heating experiments in Doublet III began in September 1978. In the period through July 1979, the primary emphasis has been on shaping the plasma to obtain a steady-state noncircular discharge, and on making preliminary measurements of the plasma characteristics. A summary of these studies is presented in this paper.

Future plans call for the addition of $7 \mathrm{MW}$ of $80 \mathrm{kV}$ hydrogen neutral beam injection. Initiation of beam heating experiments is presently scheduled for mid-1980. The ultimate goal of these experiments is on determine the limiting $\beta$ for various noncircular configurations.

What is presented herein 1 s essenclally a progress teport un a continuing reocarch effort. Many of the results are preliminary or incomplete. In some cases, key 
diagnostic measurements that might clarify important points are not yet available. Care should be taken not to interpret these results as being other than an account of what has to date been observed in Doublet III.

\section{MACHINE PARAMETERS}

Doublet III (Fig. 1) is designed to accommodate a variety of plasma cross-sections, ranging from circular to doublet, with a vertical elongation of up to 3.2 . The vacuum vessel is surrounded by 24 plasma shaping coils (F-coils), used to control the position and shape of the discharge. The ohmic-heating and toroidal field coil systems are conventional, with the exception that the toruidal coil has a demountable joint at the top to facilitate assembly of the poloidal coils. All coils are water-cooled copper. Various machine and operating parameters are summarized in Table I.

TABLE I

\section{Doublet III Parameters}

MAJOR RADIUS

MAXIMUM PLASMA WIDTH (2a)

MAXIMUM PLASMA HEIGHT (2b)

TOROIDAL FIELD

OHMIC HEATING FLUX SWING

DESIGN PLASMA CURRENT

DESIGN PULSE LENGTH

\section{PLASMA SHAPING}

Control of the poloidal magnetic flux 1inking the F-colls allows the cross-section and position of the discharge to be varied. The F-coils are arranged in several parallel-connected groups, (Fig. 2), each with a power supply in series. The voltages produced by these supplies determine the coil fluxes, and hence the plasma shape. The parallel connection of the $\mathrm{F}$-colls provides passive stability against axisymmetric motion of the plasma, especially for vertical displacements.

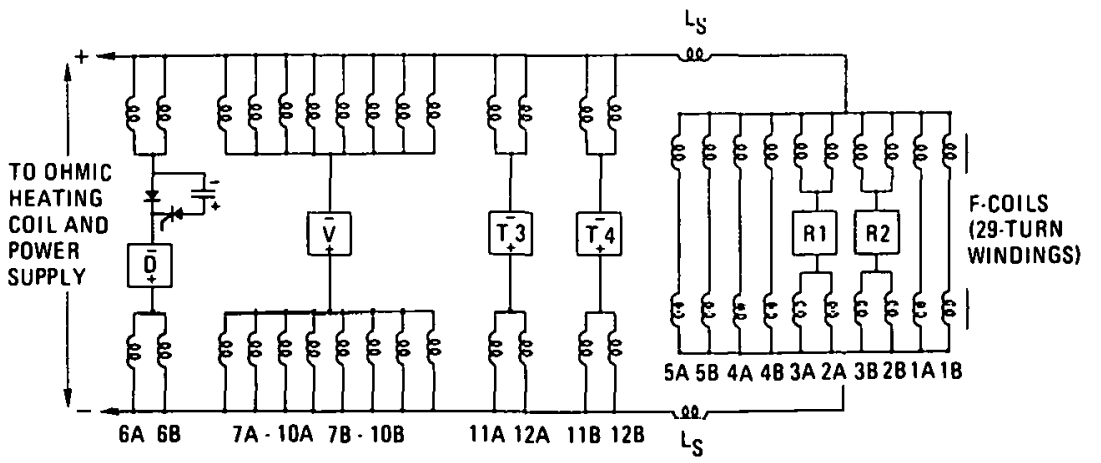

Fig. 2. Poloidal circult for doublet shaping 
To minimize the coil terminal voltage, the F-colls are split 1nto two 29-turn windings with the shaping supplies connected between. The total number of turns in each F-coil (58) is chosen such that connecting the F-colls in parallel with the 61-turn ohmic heating coil inductively decouples the F-coll system from the ohmic heating coil. This ensures that currents flow in the F-colls only due to the presence of plasma current.

Three basic types of discharges can be produced in Doublet III (Figs. 3 and 4 ). The choice of which F-coils the shaping supplies are connected to determines whether the discharge forms only in one half of the vessel (ellipse) or symmetrically in both halves (droplet or doublet). The magnitude of the shaping flux applied to the outer midplane coils determines whether the discharge breaks into two independent current channels (droplets) or remains connected, with an internal separatrix (doublet).

The shaping functions of the various power supplies are more clearly illustrated by the one-line schematic equivalent circuits shown in Fig. 5. The vertical field required to maintain radial equilibrium is provided by the combination of a $16 \mathrm{mH}$ inductor $L_{S}$ in series with the inner Fcoils and the $V$ (vertical) supply in series with the outer F-coils. For the case of an elliptical plasma, connection of the supply to the bottom F-coils also causes the discharge to localize in the upper half of the vessel. Fine tuning of the plasma shape along the inner F-colls and compensation for the effects of F-roil resistance are accomplished by supplies $R 1$ in series with F-coils $2 \mathrm{~A}$ and $3 A$ and $R 2$ in series with $F$-coils $2 B$ and $3 B$.

For doublet or droplet shaping, the flux required to control the plasma shape at the midplane is provided by the $D$ (douhllet) supply, assisted by a capacitor discharge circuit during the initial plasma current rise. Fine tuning of the plasma height and shape is provided by "tweaker" supplies T3 and T4 that control the flux at the top and bottom F-coils. Again, resistance compensation supplies $\mathrm{R} 1$ and R2 minimize differences in the shaping flux on the inner F-colls due to finite F-coll resistance. Specifications of the shaping supplies are summarized in Tals.te T.T.

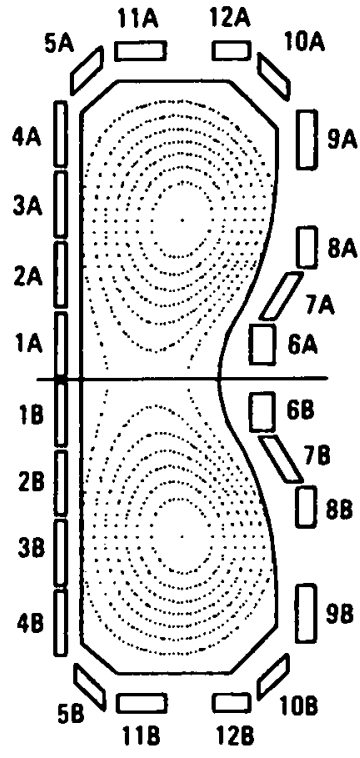

Fig. 3. Typical doublet magnetic configuration (shot 4890 at $t=400$ ms, see Fig. 10)
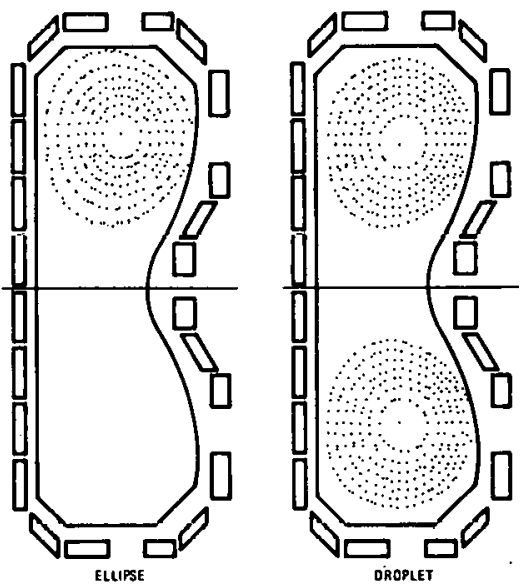

Fig. 4. Typical droplet and ellipse magnetic configurations 

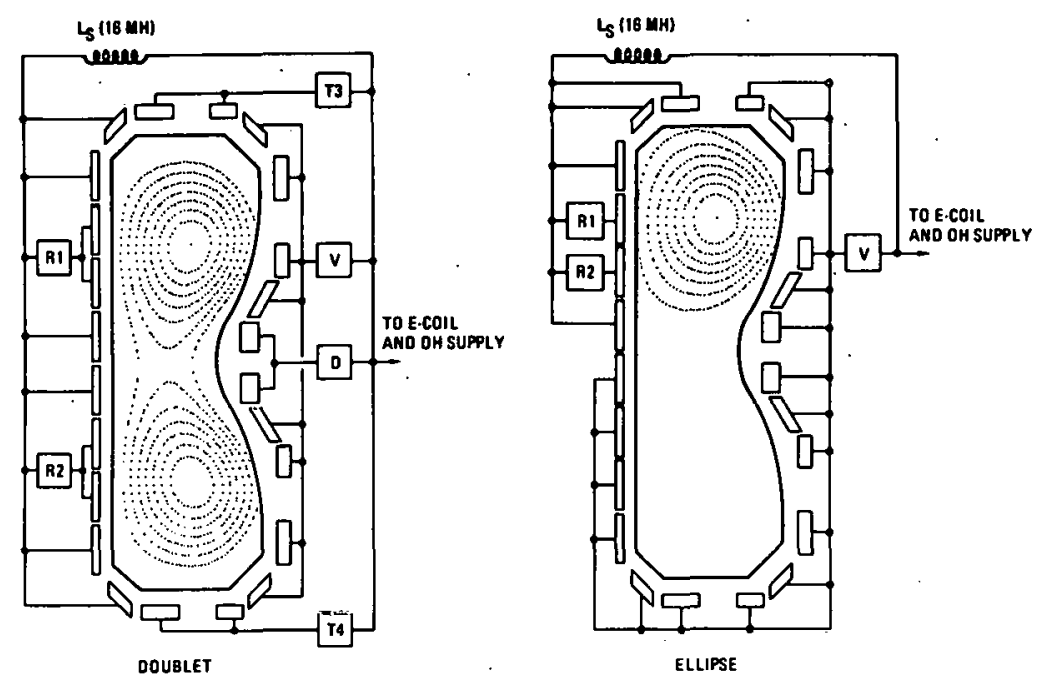

Fig. 5. One-line circuits for plasma shaping

TABLE II

Doublet III Plasma Shaping Power Supplies

\begin{tabular}{llclc} 
SUPPLY & $\begin{array}{c}\text { VOLTAGE } \\
(\mathrm{V})\end{array}$ & $\begin{array}{c}\text { CURRENT } \\
(\mathrm{kA})\end{array}$ & \multicolumn{1}{c}{ TYPE } & $\begin{array}{c}\text { STEP RESPONSE TIME } \\
(\mathrm{ms})\end{array}$ \\
\hline $\mathrm{D}$ & 600 & 14 & $60 \mathrm{~Hz}, 12 \mathrm{pulse}$ & 8 \\
$\mathrm{~V}$ & 600 & 21 & $60 \mathrm{~Hz}, 12$ pulse & 8 \\
T3, T4 & 400 & 3 & SCR CHOPPER & 0.2 \\
R1, R2 & $0-150$ & 3 & $60 \mathrm{~Hz}, 6 \mathrm{pulse}$ & 16 \\
\hline
\end{tabular}

In degcribing the shape of droplet and duublet plasmas, the quant1ty

$$
P_{s} \equiv \frac{\psi_{\max }-\psi_{\text {sep }}}{\psi_{\max }-\psi_{1 \text { im }}}
$$

Lis a useful paramecter. Here $\psi_{\max }, \psi_{\text {sep }}$ and $\psi_{1 \mathrm{im}}$ are respectively the flux values at the elliptic axes, separatrix and Iimfter, Doublets have $0<P_{3} \leq 100 \%$, while droplets have $P_{S}>100 \%$, i.e., the separatrix is outside the plasma surface. The configuration shown in Fig. 3 has $P_{s} \cong 90 \%$ (doublet) and for the droplet In Fig. 4 $P_{S} \cong 180 \%$. Droplets with $P_{S} \sim 200 \%$ are nearly circular (b/a $\left.\leq 1.1\right)$. Droplets with $P_{S} \rightarrow 100 \%$ are more teardrop-like, with $\mathrm{b} / \mathrm{a} \rightarrow 1.4$.

\section{SHAPE MEASUREMENT}

The shape of the external flux surfaces of the plasma is determined from measurements of the flux and poloidal fleld 1mmediately outside the vacuum vessel. There are two magnetic diagnostic systems (Fig. 6): a set of 24 psi-loops (one-turn voltage loops) located on the center of the plasma-facing side of each F-coll, and a serles of 12 "partial Rogowski" (PR) magnetic probes located between the vessel and the F-colls. The partial Rogowski's are fabricated by cutting a standard Rogowski coll into 12 segments, each spanning two F-coils, hence the terminology 
"partial Rogowski." The PR coils are labeled by the respective F-colls they span, e.g., PR12A over F-coils $1 A$ and $2 A$, PR511B over coils $5 B$ and $11 B$, etc. Here $A$ and $B$ designate the upper and lower halves of the machine.

The shape analysis procedure uses the General Atomic MHD code GAQ (McClain and Brown, 1977), a free-boundary algorithm that calculates plasma equilibrium in an F-coil system. In the data analysis mode, the experimentally measured psi-loop flux values are used as input boundary conditions. The quantities to be determined are the plasma current density and pressure profiles $\left(\beta_{p}\right)$. To obtain these, one makes an initial guess as to the current profile and $\beta_{p}$ [aided by measurements of $T_{e}(r)$ and $\left.n(r)\right]$ and then uses the code to find the corresponding MHD equilibrium. Agreement between the computed and actual plasma is tested by comparing the measured $P R$ values with those computed by the code. The current profile and $\beta_{p}$ are adjusted until satisfactory agreement is obtained (Fig. 7). This procedure makes it possible to determine $P_{S}$ to about $\pm 5 \%$.

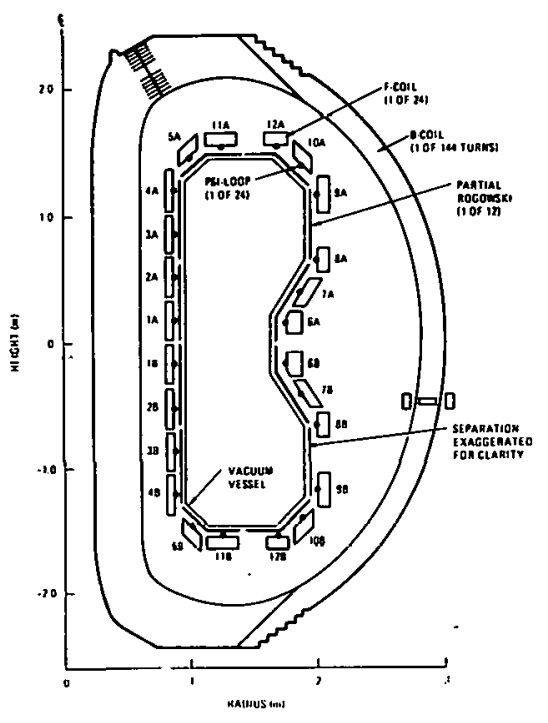

Fig. 6. Magnetic diagnostics used for plasma shape measurement

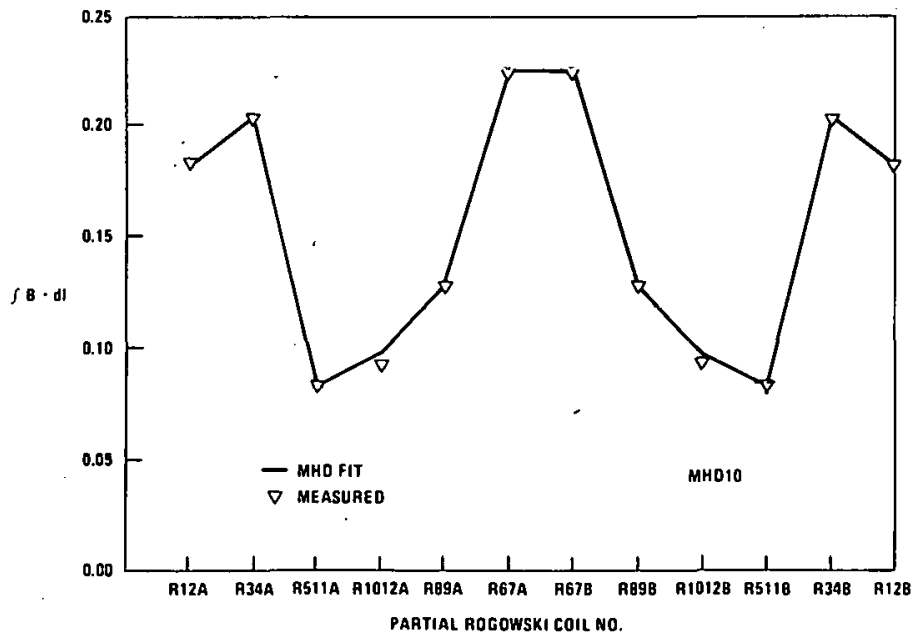

Fig. 7. Comparison of measured and computed partial Rogowolki oignolo for Fig: 3

It is important to realize that this MHD fitting procedure determines the correct shape of thie uuterunst flux surfaces of the plasma, but does not necessarily give much information about the internal details of the current distribution. A priori MHD simulations show that, in Doublet III, the same external plasma shape can be obtafned with rather different profiles. In such cases, the internal flux 
distribution, i.e., $P_{S}$, can vary by about $\pm 10 \%$. However, if the cholce of profiles is restricted to physically reasonable monotonic functions of $\psi$, the variation in $P_{S}$ is less than $\pm 5 \%$; and it is still meaningful to use $P_{S}$ as a shape parameter.

The MHD analysis procedure extracts the maximum possible amount of information available in the magnetic data and automatically incorporates the constraint of MHD equilibrium. However, since it requires the use of a large-scale computer and some trial and error, it is sultable only for off-line analysis of limited amounts of data.

Approximate methods based on the partial Rogowski signals have been developed to overcome these limitations. Study of a large number of simulated and experimental equilibria has established that the quantity

$$
\mathrm{P}_{\mathrm{s}}^{*} \equiv 2-1.15 \cdot \frac{\mathrm{PR} 12}{\mathrm{PR} 34}
$$

approximates $P_{S}$ to within $\pm 10 \%$. An oscilliscope display of $P_{S}^{*}$ (calculated with analog electronics) has proven to be extremely useful in tuning the plasma shaping.

\section{DISCHARGE CHARACTERISTICS}

Waveforms for a typical droplet discharge are shown in Fig. 8. The plasma current Is about $650 \mathrm{kA}$, of which about $270 \mathrm{kA}$ is in the upper half of the vessel where most of the diagnostic measurements are made. The plasma shape is nearly circular $(b / a \cong 1.1)$.

The basic waveforms shown in Fig. 8 are characteristic of all three types of discharges, with the exception of the magnitude of the plasma current and the time required to reach the nominal current flattop. Typically, the loop voltage falls to below $2 \mathrm{~V}$ about $200 \mathrm{msec}$ after the initiation of the discharge. Gas injection at a constant rate, typically 50 Torr-l/sec, results in an approximately linear rise in density during the $450 \mathrm{msec}$ duration of the discharge. The central temperature fialls as the density increases.

The waveforms for the elliprifal dischargeo are simil,ar to those shown in Fig. 8 . For this case, the discharge initially fills the entire vessel, but after $10 \mathrm{msec}$ concentrates in the upper half as soon as the plasma becomes hot enough to recognize the field lines as paths of high thermal conductivity to the walls and limiter. Although extensive studies of the time dependence of the plasma shape have nol yet been carried out, the partial Rogowski and psi-loop signals indicate that the clongatiun ls essencialiy constant during the flattop phase of the discharge. The magnetic conflguration is shown in Fig. 4.
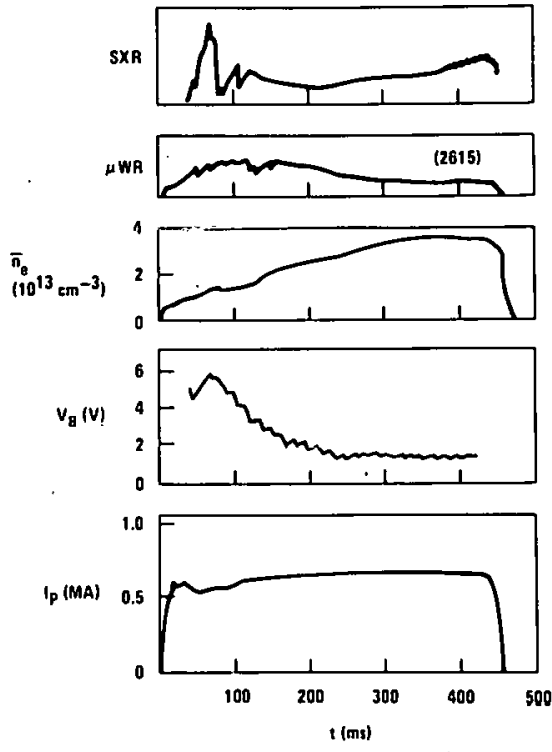

F1g. 8. Typical droplet discharge waveforms 
The shaping of doublet plasmas involves several additional control aspects beyond the vertical fleld control and resistive compensation used for ellipses. Specifically, both the amount of midplane flux (F-coils $6 \mathrm{~A}$ and $6 \mathrm{~B}$ ) and end flux (coils $11 \mathrm{~A}-12 \mathrm{~A}$ and $11 \mathrm{~B}-12 \mathrm{~B}$ ) must be controlled to follow changes in the magnitude and distribution of the plasma current. Typical flux waveforms are shown in Fig. 9. The ratio of doublet shaping flux to plasma current, $\psi_{6} / I_{p}$, is initially high when the plasma current profile is broad. Later in the discharge, when the profile peaks, the relative shaping flux must be reduced to avoid breaking the plasma into droplets.

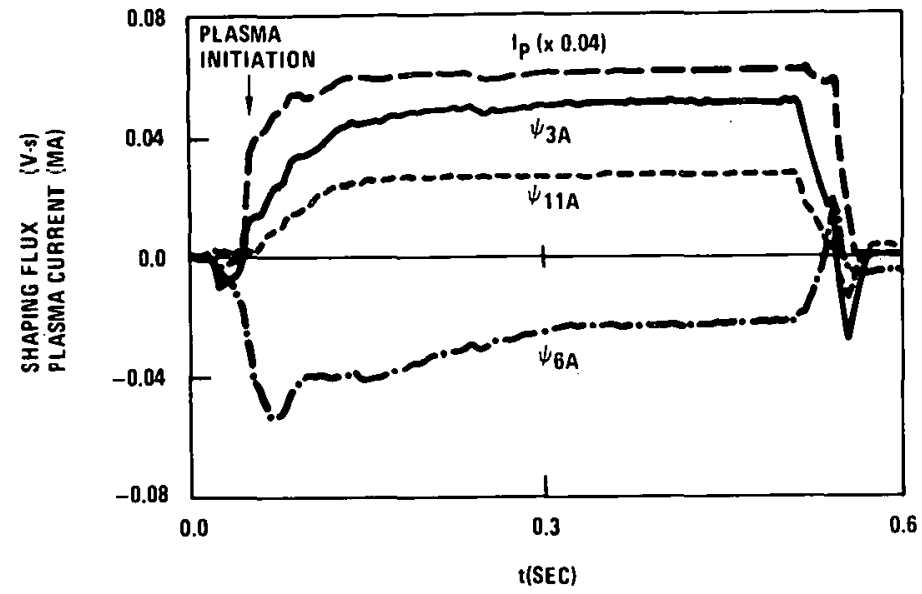

Fig. 9. Typical flux and plasma current waveforms to maintain a nearly constant doublet shape

Obtaining a stable doublet discharge with low loop voltage requires fairly precise control of the dnublet and vertical ficld fluxes. Although it is posstble to achieve the required control precision using preprogrammed voltage vs. time waveforms for the various supplies, the implementation of feedback control of the doublet and vertical field supplies has improved the reproducibility of the discharges. Similarly, servo control of the tweaker power supplies to maintain equal flux values at the top and bottom of the discharge has resulted in improved discharge symmetry: Servo control of the $R$ supplies to maiulalu eyual flux along the inside F-coil wall is necessary to avold distortion of the plasma shape due to the effects of finile $\mathrm{F}$-coll resistance.

Typical plasma waveforms for a doublet discharge are shown in Fig. 10 . In the first $150 \mathrm{msec}$ of the discharge, the plasma shape undergoes a series of $\mathbf{n}=0$, $\mathrm{m}=2$ oscillations, eventually settling down to a quiescent phase in which the shape stabilizes at a $90 \%$ doublet. The shape oscillations are associated with a sudden broadening ( $\sim 1 \mathrm{~ms}$ ) of the electron temperature profile (Fig. 11), (possibly due to internal. MHD activity) followed by a slower return ( $20 \mathrm{~ms}$ ) to a peaked profile. Large amplitude shape oscillations also result in increased wall and limiter interaction. In extreme cases, this interaction results in complete dieruption of the discharge. More typically, only a minor decrease in current occurs and the discharge survives. 
After approximately $150 \mathrm{msec}$, the discharge becomes quiescent, with a reduced level of shape oscillations, a low loop voltage and a slowly varying plasma shape. Fluctuations in the radial position and height are less than $1 \mathrm{~cm}$. The electron temperature profile becomes centrally peaked and is essentially stationary.

H1gher levels of Mirnov oscillations are observed during the initial phase. The shape oscillations are accompanied by bursts of Mirnov activity, which are absent during the quiescent phase. The mode numbers of the poloidal oscillations have not yet been identified. In general, the magnetic probe fluctuation signals are stochastic, without obvious sinusoidal components. Investigation of this aspect of the discharge is continuing.

Classical sawtooth oscillations with $\mathrm{m}=2$ precursors have been observed in the central soft $x$-ray emission from droplet plasmas, but so far not from ellipses or doublets. Some doublet plasmas exhibit low amplitude, high-frequency ( $10 \mathrm{kHz}$ ) soft $x$-ray fluctuations during the flat top phase, but the location and mode has not yet been identifled. The current density inferred from the electron temperature profile and constant $Z_{\text {eff }}$ over the discharge implies $q(0)$ is near unity in the center of the discharge $(e . g ., q(0)=$ 0.9 for shot number 4890 at $400 \mathrm{msec}$ ). The role of sawtooth activity in noncircular plasmas is clearly a topic of considerable interest and one that requires additional study.

The plasma discharges are sometimes terminated prematurely by disruptions. Classical disruptive phenomena are observed in elliptical plasmas: a sudden $\mathrm{n}=0, \mathrm{~m}=0$ expansion of the current channel, an inward radial shift and negative voltage spikes. In droplet plasmas, similar phenomena are observed, with the exception that the negative voltage spike is not as prominent. The two droplet current channels evolve independently, with one often surviving after the other disrupts.

The mechanism responsible for plasma current termination in doublete is 1 coo clear. A sudden $\mathrm{n}=0, \mathrm{~m}=0$ expansion of one current channel and an inward radlal shifr is observed in many cases. Disruption of one channel occurs first and invariably precipitates a disruption in the other channel 5 or $10 \mathrm{msec}$ later.
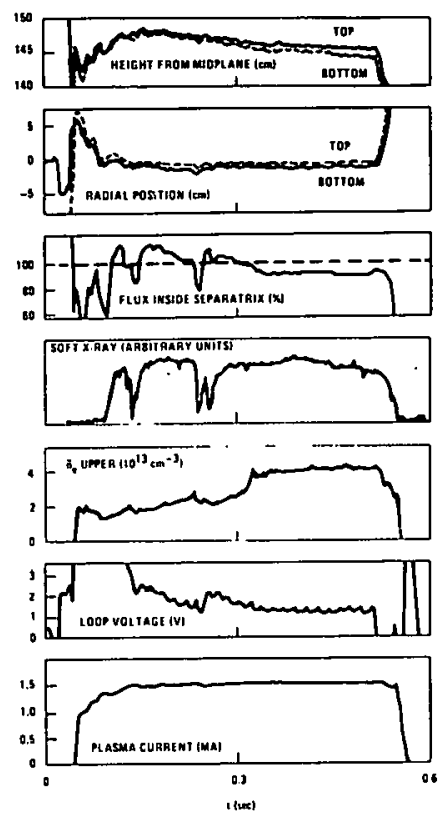

Fig. 10. Typical doublet discharge waveforms

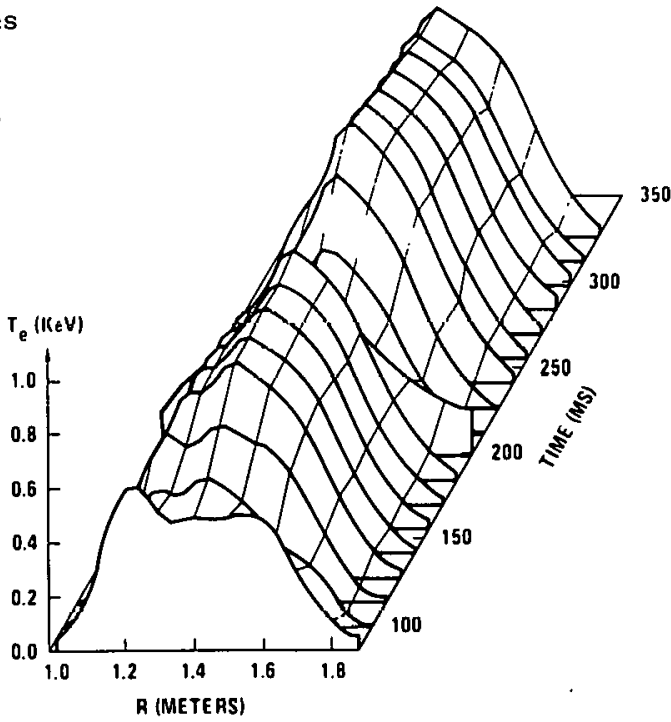

Fig. 11. Electron temperature profile evolution 
The disruption also results in an immediate change in plasma configuration, with both current channels shifting radially inward and towards the midplane. A negative voltage spike is not observed in a doublet disruption.

Loss of vertical equilibrium appears to be a second current termination mechanism for doublets. In this case, the flux percentage begins to drop and the p.lasma suddenly collapses to an ellipse at the midplane, a configuration which is vertically unstable. The shape changes that occur in this process are similar to those of the current disruption described above: an inward radial shift and coalescence at the midplane of both current channels. In some cases, this configuration shift is slow ( $50 \mathrm{msec}$ ) and up/down symmetric; more frequently, it is faster (< $10 \mathrm{msec}$ ) and very similar in appearance to a true disruption. additional studies are required to clarify the causes and role of these two mechanisms.

\section{CONFINEMENT, DENSITY AND IMPURITIES}

Typical plasma parameters for the flattop phase of the three types of discharges are sumnarized in Table III. All parameters reach a steady state condition. In doublets where the evolution of the temperature profile has been measured, the profile is stationary and centrally peaked. The maximum density achieved with

TABLE III

Plasma Parameters for Steady-State Discharges

\begin{tabular}{llll} 
PARAMETER & ELLIPSE & DROPLET & DOUBLET \\
\hline $\mathrm{B}_{\mathrm{T}}(\mathrm{kG})$ & 20 & 20 & 24 \\
$\mathrm{I}_{\mathrm{p}}(\mathrm{kA})$ & 400 & 270 & 1500 \\
Minimum Voltage & 1.6 & 1.6 & 1.6 \\
$\mathrm{q}(0)$ & $\sim 1$ & 1 & $\sim 1$ \\
$\overline{\mathrm{n}}_{\mathrm{e}}\left(10^{13} \mathrm{~cm}^{-3}\right)$ & $2-3$ & $2.5-3.5$ & $3-5$ \\
$\mathrm{~T}_{\mathrm{e}}(0)(\mathrm{keV})$ & $0.7-1.0$ & $0.5-1.0$ & $0.5-1.1$ \\
$M_{\text {Minimum Z }}$ & 2 & 1.1 & 2 \\
$\mathrm{~T}_{\mathrm{E}}^{\mathrm{e}}(0)(\mathrm{ms})$ & $10-17$ & $15-25$ & $15-30$
\end{tabular}

doublet plasmas is in good agreement with the $B_{t} / R$ scaling observed in other clean, high-density experiments (Apgar and co-workers, 1977; Bol and cu-workers, 1979; Engelhardt and co-workers, 1979; Fielding and co-workers, 1977; Konoshima and coworkers, 1978; Murakami and co-workers, 1979) (F1g, 12). The maximum line average density uliained Lo date is $5 \times 10^{13} \mathrm{~cm}^{-3}$. The density obtained in droplets and ellipses is somewhat less, probably due to the limited amount of experimental time devoted to these plasmas.

The central electron energy confinement increases with plasma density (Fig. 13). The average slope of the data at high density is similar to that observed for the global electron confinement in PLT with titanium gettering (Bol and co-workers, 1979). The best electron confinement obtained so far is $\tau_{\mathrm{E}}^{\mathrm{e}}(0)=28 \mathrm{msec}$ at $\cdot \overline{\mathrm{n}}_{\mathrm{e}}=$ $3.9 \times 10^{14} \mathrm{~cm}^{-3}$. Preliminary estimates of the global electron confinement based on the radiometer profile data indicate that the global confinement is about $80 \pm$ $10 \%$ of the central confinement.

Although the ion temperature has not been measured, code simulations using neoclassical ion conductivity indicate that the ion and electron temperatures should 
be nearly equal at the higher densities. Thus, the total confinement time for doublets presumably is $40-50 \mathrm{msec}$, assuming $\mathrm{T}_{\mathrm{e}}=\mathrm{T}_{i}$.

The variations of confinement with plasma shape presented in Table III appear to be wholely due to the density dependence of the electron confinement. The confinement time normalized by density is essentially the same for all three shapes. However, at this point, it is possible to state that the electron confincment in doublets is at least equal to that for circles and ellipses. Future studies of the shape dependence of the confinement (if any) will require more complete and accurate measurements.

Impurity measurements are still in a relatively preliminary state. Auger analysis of samples exposed to the discharge cleaning plasma and residual gas analysis of the impurities evulved during plasma discharges suggest that carbon is the dominant low -2 contaminant. Chromium and molybdenum lines are prominant in the soft $x$-ray spectrum (Fig. 14). The concentration inferred from the soft $x$-ray intensity is about $3 \times 10^{9} \mathrm{~cm}^{-3}$. Tantalum (the primary limiter material) is not observed in the soft $x$-ray region, indicating that the concentration is less than $10^{9} \mathrm{~cm}^{-3}$.

Auger analysis shows that molybdenum is the dominant heavy metal transported during plasma operation ( $5 \%$ monolayer $/ 40$ discharges), with tantalum nearly an order of magnitude less. This seems to corroborate the soft $x$-ray data that molybdenum (from the secondary limiters) and chromium (from the wa11) are dominant high-Z impurities. For coronal equilibrium, the measured impurity concentrations would imply $\mathrm{P}_{\mathrm{rad}} / \mathrm{P}_{\mathrm{OH}} \sim 10 \%$ in the center of the plasma. This estimate seems to be supported by the relatively good electron confinement, which is similar to that obtained in machines known to be free from significant high-z radiation. Forthcoming bolometric and vacuum ultraviolet spectroscop1c measurements of the plasma radiation are expected to clarify the impurity question.
Fig. 12. Comparison of maximum density achieved in Doublet III with other experiments
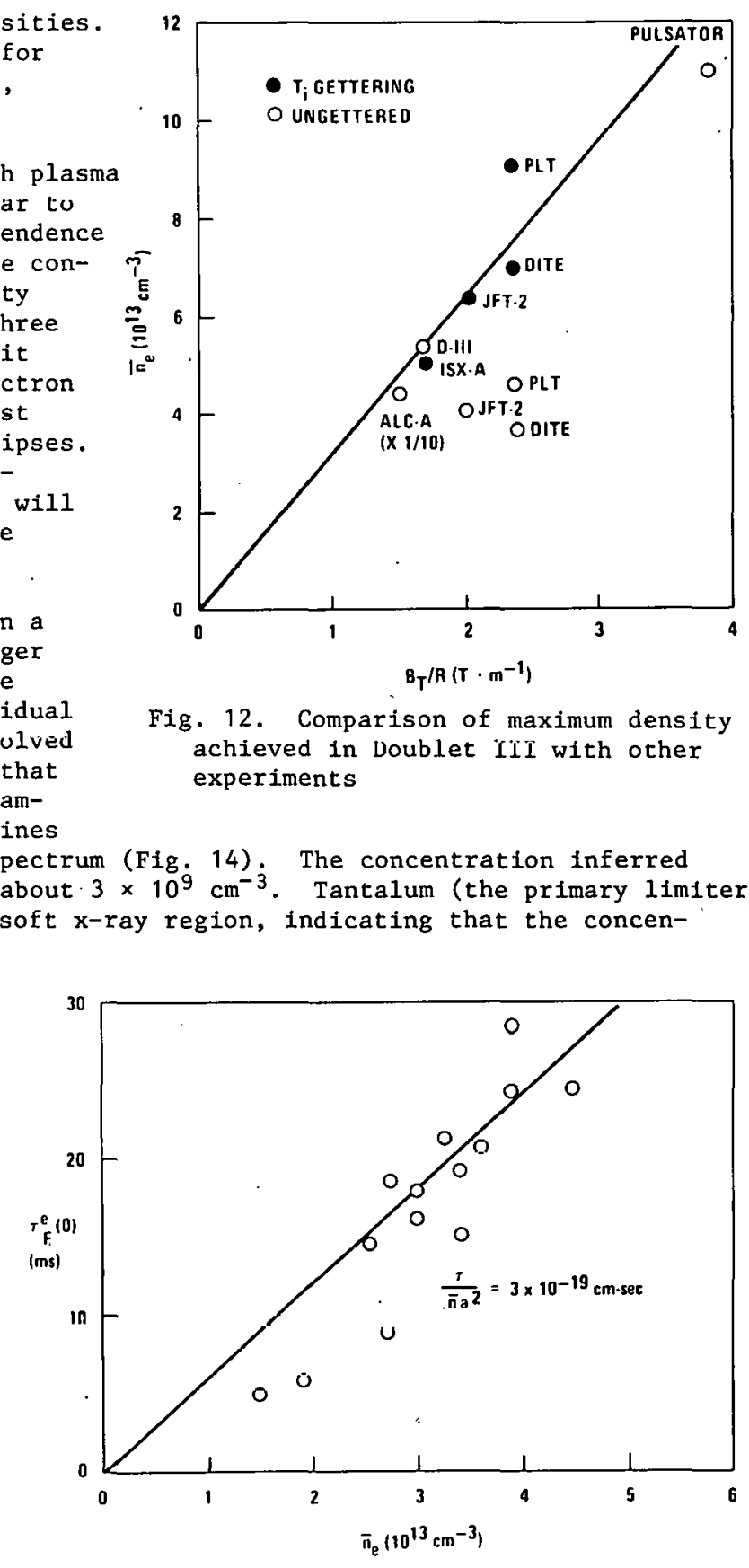

Fig. 13. Dependence of doublet central electron confinement on plasina density 


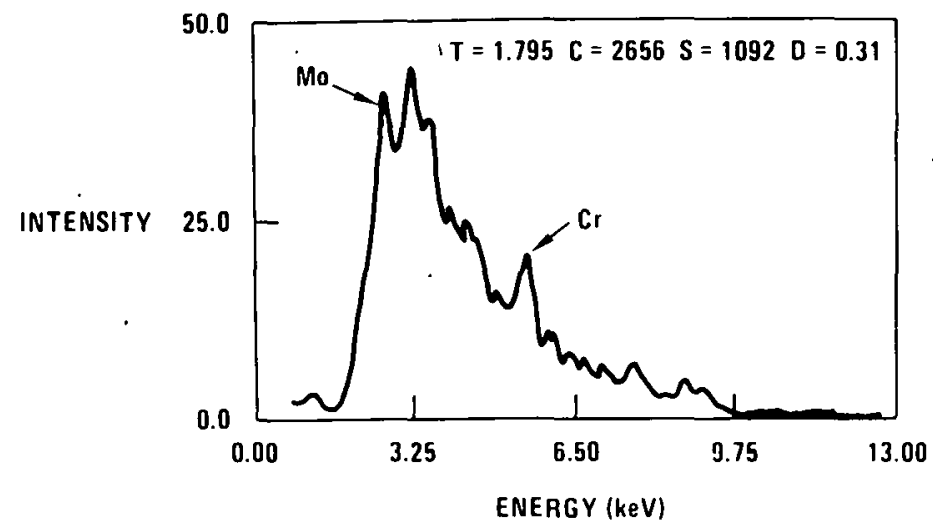

Fig. 14. Soft $x$-ray spectrum obtained in a doublet plasma

\section{SUMMARY}

Steady-state circular, elliptical and doublet plasmas with low loop voltages and low levels of internal MHD activity have been produced. The magnetic configurations during the flattop phase are essentially constant. The doublets have about $90 \%$ of their poloidal flux inside the separatrix. Radiometer measurements show that the electron temperature profile is stationary and centrally peaked. The electron confinement and maximum plasma density achieved to date are in good agreement with "standard" scaling laws. Indirect evidence suggests that the power balance in the central portion of the plasma is not dominated by high- 2 impurity line radiation.

\section{ACKNOWLEDGMENTS}

The studies reported here were carried out by members of the Doublet III physics, plasma diagnostics and operations groups: S. Adcock, C. Armentrout, D. Baker, J. Baur, F. Blau, N. Brooks, R. Callis, R. Chase, J. DeBoo, J. deGrassie, S. Ejima, E. Fairbanks, R. Fisher, W. Guss, C. Hsieh, G. Jackson, G. Jahns, J. Lohr, M. Mahdavi, F. Marcus, F. Parlanget, P. Petereen, S. Sekitt, K. Seraydarian, L. Srnka ttt, R. Stambaugh, T. Tamano, T. Taylor and J. Wesley.

The Auger surface analysis measurements were done by $R$, Clausing, L. Emerson and L. Heatherly from Oak Ridge National Laboratory, using a portable surface analysis system supplied by Oak Ridge National Laboratory.

l'his manuscript was prepared with the assistance of J. Wesley and J. DeBoo.

*Research Supported by Department of Energy Contract DE-AT03-76ET51011. tOn leave from Association Euratom CEA GRENOBLE, France.

††Japan Atomic Energy Research Institute, Tokai Research Establishment, Japan.

t+†Present address: Exxon Production Research Company, Houston, TX. 77001.

\section{REFERENCES}

Apgar, E., B. Coppi, A. Gondhalekar, H. Helaua, D. Komm, F. Martin, B. Montgomery, D. Pappas, R. Parker and D. Overske1 (1977). High-Density and Collisional rlaśma Kègimes in the Alcator Programme. In plasma Physics and conrrolled Nuclear Fuston Research (Proc. 6th Intl. Conf., Berchtesgaden, 1976), Vol. I. IAEA, Vienna. p. 247-257. 
Bol, K., V. Arunasalam, M. B1tter, D. Boyd, K. Brau, N. Breta, J. Bussac, S. Cohen, P. Colestock, S. Davis, D. Dimock, F. Dylla, D. Eames, P. Efthimion, H. Eubank, R. J. Goldston, R. J. Hawryluk, K. W. Hill, E. Hinnov, J. Hosea, H. Hsuan, F. Jobes, D. Johnson, E. Mazzucato, S. Medley, E. Meservey, N. Sauthoff, G. Schmidt, F. Stauffer, W. Stodiek, J. Strachan, S. Suckewer, G. Ta1t, M. Ulrickson and S. Von Goeller (1979). Radiation, Impurity Effects, Instability Characteristics and Transport in Ohmically Heated Plasmas in the PLT Tokamak. In Plasma Physics and Controlled Nuclear Fusion Research (Proc. 7th Int1. Conf., Innsbruck, 1978), Vol. I., IAEA, Vienna. p. 11-33.

Engelhardt, W., O. Klüber, D. Meisel, H. Murmann, S. Sesnic, G. Fussmann, E. Glock, N. Gottardi, F. Karger, G. Lisitano, H. M. Mayer and F. Wagner (1979). Accumulation of Impurities and Stability Behavior in the High-Density Regime of Pulsator. In Plasma Physics and Controlled Nuclear Fusion Research (Proc. 7 th Int1. Conf., Innsbruck, 1978), Vol. I., IAEA, V1enna. p. 123-134.

Fielding, S. J., J. Hugill, G. M. McCracken, J. W. M. Paul, R. Prentice and P. E. Stott (1977). High-Density Discharges with Gettered Torus Walls in DITE. Nuclear Fusion, 17, 1382-1385.

F1sher, R. K., S. J. Adcock, J. F. Baur, N. H. Brooks, J. C. DeBoo, K. L. Freeman, W. C. Guss, F. J. Helton, C. L. Hsleh, T. H. Jensen, A. F. Lietzke, J. M. Lohr, M. A. Mahdavi, K. Matsuda, C. P. Moeller, T. Ohkawa, N. Ohyabu, S. C. Prager, J. M. Rawls, T. Tamano, V. Vanek and T. S. Wang (1977). Studies of Doublet Plasmas in Doublet IIA. Phys. Rev. Lett., 39, 622-625.

Jensen, T. H., R. K. Fisher, C. L. Hsieh, M. A. Mahdavi, V. Vanek and T. Ohkawa (1975). Confinement of Plasma in the Doublet II Device. Phys. Rev. Lett., 34, $257-260$.

Konoshima, S., N. Fujisawa, M. Maeno, N. Suzuk1, T. Tamamoto, Y. Gomay, T. Hirayama, M. Shimada, K. Uehara, A. Funahashi, T. Matoba, T. Kawakami, K. Takahashi, T. Shoji, K. Kumagai, S. Kasai, H. Takeuch1, T. Yamauch1, T. Sugie, M. Shiho and A. Nagashima (1978). Improvement of Plasma Parameters by Titanium Gettering in the JFT-2 Tokamak. Journal Nuclear Materials, 76-77, $581-586$.

McClain, F. W. and B. B. Brown (1977). GAQ, A Computer Program to Find and Analyze Axisymmetric MHD Plasma Equilibria. General Atomic Co. Report No. GA-A14490.

Murakami, M., G. H. Néilson, H. C. Howe, T. C. Jernigan, S. C. Bates, C. E. Bush, R. J. Colchin, J. L. Dunlap, P. H. Edmonds, K. W. Hill, R. C. Esler, H. E. Ketterer, P. W. King, D. W. McNelll, J. T. Mihalczo, R. V. Neidigh, V. K. Pare and M. J. Saltmarsh (1979). Plasma Confinement Studies in the ISX-A Tokamak. Phys. Rev. Lett., 42, 655-658.

Ohkawa, T. and H. G. Voories (1969). Plasma-Current Multipole Experiments. Phys. Rov. Lott., 22, 1275-1277.

\section{DISCUSSLIUN (on paper presented by J. DeBoo)}

HAWRYLUK

When you were plotting the confinement time data for PLT were you using total energy confinement time, electron energy confinement time, or what? DEBOO

The PLT data prescnced was a global electron confinement time. 'I'he doublet data presented consisted of central values of the electron confinement time. So both groups of data referred to electron confinement times only and the PLT data were average values and Doublet IIT data were central values. Preliminary estimates of the global. electron energy confinement based on radial temperature profiles 
indicate that the global confinement is about $80 \%$ of the central confinement value. The total energy confinement time was not quoted because we have not yet made an ion temperature measurement. However, based on Artsimovich scaling, the ion and electron temperatures are similar, so that the total central energy confinement time is probably about twice the electron-only value.

\section{HAWRYLUK}

Werc the currents in thuse discharges that disrupted at the end well controlled? It aeems to me that they disappear rather rapidly.

\section{DEBOO}

The termination was usually from a disruption. I discussed the two typical modes that terminates the current for a doublet. It is a disruption - not a slow dropoff. in current due to the volt-sec limit of the oluic power supply.

\section{HAWRYLUK}

It wasn't clear to me what the difference was between a doublet and a droplet or circle. Was there any improvement in the confinement time in the discharge shape or any change?

\section{DEBOO}

There was only a small increase in confinement for the doublet compared to the circle and this is most likely due to slightly higher densities achieved in doublets because little time was spent optimizing the density in circles. The confinement time normalized by density was essentially the same for all three shapes discussed. What we are really pointing out is that the electron confinement in doublets is at least equal to that in circles. We believe we can control the shape of the doublet and keep it stationary. Attempts will now be made to improve the confinement by increasing the electron density.

\section{CLARKE}

You said that the purpose of this serles of experiments was to investigate the properly of doublet plasmas in a high temperature regime. Now have you learned enough to date to be able to increase the density to the point where you can inject beams into this doublet and heat it and see if there actually is a difference, because it seems to me that you have not demonstrated any difference so far?

\section{DEBOO}

We are not stressing any difference so far. We are at the point where we are beginning to try to increase the electron density. We would like at least $7 \times 10^{13}$ line average density to inject neutral beams and keep beam shine through acceptably low. At the moment, the maximum line average density we have achieved is about $5 \times 10^{13}$. We have not spent much time trying to optimize the gas-puffing that has been done into these discharges. Also, if you recall the Murakami density scaling plot that I showed, several machines had cases of gettered and ungettered discharges. In these machines, gettering increased the density. This is another possible approach to increase our density.

\section{DUECHS}

T.er's congratulate the Doublet III team on their world recurd in the currenc reached. 
Armentrout, C. Baker, D. R. Baur, J. F. Beal, J. W. Bernard, L. Blàu, F. Bourque, R. F. Brooks, N. H. Burke, J. M. Burnett, S. C. Burrell, K. H. Callis, R. W. Chan, V. S. Chen, K.Y.V. Chiu, S. C. Chu, Cheng Colleraine, A. P. Dalessandro, J. A. DeBoo, J. C. DeGrassie, J. S. Dobrott, D. R. Dominguez, R. R. Ejima, s.

Ensberg, E. S. Fisher, R. K. Freeman, R. L. Gilleland, J. R. Goforth, R. Guest, G. E. Guss, W. Harder, C. R. Harvey, R. W. Helton, F. J. Hino, $T$.

Holland, $M$. Hong, $\mathrm{R}$. Hopkins, G. R. Hsieh, C. L. Hubbard, E. L. Hsu, J. Jackson, G. L. Jensen, T. II. Jahns, G.

Kamperschrocr, J.

Karin, S.

Kohli, J.

LaHaye, R.

Levy, M.
Lohr, J . Luxon, J. L. Mahdavi, M. A. Marcus, F. Matsuda, K. McHarg, B. Miller, P. H. Miller, R. L. Moeller, C. P. Moore, R. W. Nordheim, L. W. Ohyabu, N. Parks, P. Parker, J. W. Petersen, P. I. Petrie, T. Peuron, U. Pfeiffer, W. Prater, R. Purcel1, J. R. Rawls, J. M. Rovner, L. Sager, P. H. Saito, M. Schaffer, J. J. Smith, J. N. Smith, J. R. Stambaugh, R. Tamano, $T$. Taylor, P. Taylor, $\mathrm{T}$. Toffolo, W. Vaslow, D. F. Waltz, R. Wang, T. S. Wesley, J. C. Wong, C. Wong, $\mathrm{S} . \mathrm{K}$. Yamagishi, $T$. Rickard, C. L.

ohkawa, T.

Document Center 


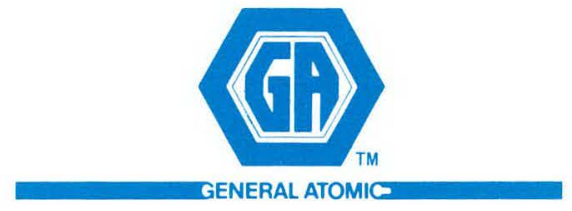

GENERAL ATOMIC COMPANY

P. O. BOX 81608

SAN DIEGO, CALIFORNIA 92138 